of the fibers, certain of the fruits, and very many other valuable commodities. In addition to all this, the animal industries, which are the sources of milk, meat, leather and wool, are dependent entirely upon herbs. The dominance of such plants in agriculture is shown by the fact that in the United States they contribute 96 per cent. of the value of the products of this fundamental industry. Without herbs, the feeding and clothing of our great populations to-day would be quite impossible, and though it is conceivable that with the advance of science civilized man might possibly dispense with woody plants, in the absence of herbs he would perforce revert almost to savagery again. Human society is essentially an herbaceous product.

Although a study of the evolution of growth-habits may not provide much information as to the natural relationships of the higher plants, as we remarked at the outset, it does nevertheless introduce us to a momentous chapter in the history of the vegetable kingdom, for these lowly forms have not only possessed the earth and determined the character of many types of animal life, but to their indispensable aid man himself really owes his career as a civilized being. EDMUNd W. SinNotT

ConNecticut Agricultural Colitge

\section{CONTRIBUTIONS OF CHEMISTRY TO THE SCIENCE AND ART OF MEDICINE ${ }^{1}$}

AT the last two meetings of this Society the general sessions have been devoted chiefly to symposia upon the contributions of the chemist to the varied phases of our American industrial development. Such emphasis is both timely and well merited. But I am impressed that this record of achievement should not be

1 Presented to the Division of Biological Chemistry of the American Chemical Society at the spring meeting at Champaign, Ill., April 17-21, 1916. closed without some consideration of the contributions of chemistry to the science and useful art of medicine. The opportunity seems likewise propitious for some suggestions as to means by which future contributions in this direction may be increased in number and in value.

The science of medicine consists in the knowledge of the normal processes of the human body (physiology) and of the nature and causes of abnormal deviations (pathology). The art of medicine includes the prevention of such deviations (hygiene), their identification (diagnosis) and their correction or alleviation by therapeutic or surgical treatment. For its present state of development each of these branches owes much to the contributions of chemistry.

Since Lavoisier's demonstration of the identity of respiration with combustion the chemist has gone step by step with the physiologist in elucidating the normal operations of the first internal combustion engine. Chemical structure of inanimate carbohydrates, lipins and proteins sheds reflected light upon the reactions and structure of living protoplasm. Colloidal chemistry, catalysis and the laws of chemical dynamics furnish all that we know of those servants of the cells, the enzymes. A new constituent of the blood is recognized to-day and to-morrow we have a new theory of metabolism. Thermochemistry is the foundation of nutrition and dietetics. The occultism of biogenesis, growth and the internal secretions is giving way before the calorimeter and the differential equation. In a word, the whole datum of physiological chemistry is a contribution to physiology and hence to the science of medicine; that much of it yet lacks practical application is no discredit to the contributor.

So much yet remains to be done in the field of chemical pathology that we are sometimes inclined to disparage past achievements. But these are not inconsiderable. In edema, concretions, diabetes and other conditions of acidosis, pathological variations in metabolism. in fever, and in numerous other directions substantial gains have been recorded. Uric acid 
has been found not guilty of most of the offenses charged in the earlier indictmentsand part of the responsibility for gout must be borne by as complete a chemical abstraction as tautomerism. But, by all odds, the greatest progress in the field of pathology is the widening recognition that in the future the important advances must be made by the chemical rather than by the histological route.

These contributions of chemistry to the science of medicine are for the most part distinctly modern. Far earlier were many of those to the art. Paracelsus gave chemistry a practical object as it emerged from the clouds of alchemy when he declared that "the object of chemistry is not to make gold, but to prepare medicines." In England, to-day, the drug store is the "Chemist's Shop," and those are not lacking in this country to whom the term chemist has a similar significance. Both are the spontaneous acknowledgment of the services of the chemist in supplying these tools of the physician. For if Paracelsus, Franciscus Sylvius and their followers of the iatrochemical school failed in their effort to develop chemistry simply as an adjunct to medicine they planted the seed which through many generations have brought forth Liebig's chloral, Ehrlich's salvarsan and the host of other synthetics which make up most of the materia medica of to-day.

The development in synthetic drugs which has followed the recognition of a connection between chemical structure and pharmacological action is a fascinating story; less, possibly, on account of actual results than because of the tantalizing probabilities. But with the establishment of the definite effects of at least some configurations and a measurement of the mutual influence of different radicals have come practical results. Guided by this information, old remedies have been improved by blocking the groups responsible for secondary effects or entirely replaced by better ones constructed to specifications. At the same time experimental pharmacology has been stimulated with the result that the modern physician has at command, for producing almost any desired effect, a variety of drugs of great reliability.
But internal therapy does not exhaust the resources of treatment and if synthetic chemistry has done much for the former it has done still more for surgery and the surgical specialties. Anesthesia and asepsis are the pillars of these structures-and the stones of the pillars are the synthetics ether, chloroform, iodoform.

Strangely enough, diagnosis is the last branch of medicine to which applied chemistry has brought substantial benefit. To be sure we have had for many years an attempt at diagnosis by means of qualitative tests. ${ }^{2}$ The urinalysis consisting only of qualitative tests for sugar and albumin is worth just as much as the feel-your-pulse, see-your-tongue, giveyou-calomel variety of clinical diagnosis and treatment-just as much and no more. The essentials of progress may be a slow and steady growth, but the results usually appear by spurts and in response to some particular incentive. In this case the impetus was furnished by the new methods of blood and urine analysis, introduced by Folin and his co-workers, which in a short time have found such wide application. Nitrogen partition in the urine and retention in the blood; urobilin index of erythrocyte destruction; differentiation and prognosis in renal and cardiac conditions; sugar and acetone elimination in diabetes; hydrogen ion concentration of the blood in other conditions of acidosis-these are but types of the applications of quantitative chemistry to clinical diagnosis. Scarcely a month in which the journals fail to report another.

In this résumé no claim is made to completeness-still less to originality-of data. But it is hoped that from a somewhat panoramic view there may be caught a conception of the truly basal relationship of chemistry to medicine. It is for this collective concept that I bespeak the consideration which it has received of few chemists and still fewer physicians. To be sure, chemistry has long occupied a more or less perfunctory position in the curricula of medical colleges-becom-

2 "As long as only qualitative methods are used in a branch of science, this can not rise to a higher stage than the descriptive one. Our knowledge is then very limited, although it may be very useful.' -Arrhenius. 
ing rather more than less perfunctory as the actual preparation of medicines, its most clearly recognized application, passed out of the hands of medical men. And chemistry is one of the subjects in which examination is required by official licensing boards. But it would require a most gifted intelligence to be able to deduce from the adventitious subjectmatter of most of these examinations any suggestion that chemistry is a fundamental part of medicine rather than some extraneous attachment.

Let me explain what I mean by perfunctory position in the medical curriculum. Until the very recent general upheaval, medical instruction in all branches left much to be desired (to be conservative in expression). Rather than an exception to this statement, the old so-called "medical chemistry" was a glaring case in point. Crowded with descriptions of natural occurrences and methods of preparation of drugs, indications, effects and dosage, clinical symptoms of poisons and their laboratory detection-so much was usurped from the provinces of pharmacy, materia medica, pharmacology and therapeutics that little space was left even in the ponderous "Textbooks of Medical Chemistry" for references to fundamental chemical principles. When included at all these latter were carefully segregated within the paragraphs of their original mention-paragraphs which could be omitted quite as easily as those on the oxides of iodine without impairment to the continuity of the text. And in practise it would appear that these paragraphs on chemical principles were omitted with even greater facility.

We may well congratulate ourselves that "all that's put behind us," far away if not long ago. Instruction in chemistry in the medical colleges is now exclusively in the charge of full-salaried teachers, most of whom are trained chemists. Matters extraneous to chemistry are no longer allowed to preempt the place which belongs to the fundamentals of chemical theory and the present-day courses in chemistry, as given in most medical colleges, are of quite the same degree of excellence as those in other professional or academic institutions.
It is satisfying to regard this improvement, but facts are not wanting which raise other questions. May we still be lacking somewhat of the highest possible efficiency? In the Standards of the Council of Medical Education of the American Medical Association, defining the "Essentials of an Acceptable Medical College," this dictum is laid down, "Nonmedical men should be selected as teachers in medical schools only under exceptional circumstances and only because medical men of equal special capacity are not available." The obvious advantage sought is the wider point of view of men trained to the practical applications of their subjects to other branches of medicine and able to direct the minds of students to these interrelationships. There is no department of instruction in which this advice of the Council has been so consistently disregarded as in the selection of chemistry teachers-and for the very good reason indicated, that "medical men of equal special capacity" were not (and are not) available. Medical instruction in chemistry is, therefore, for the most part in the hands of men adequately enough trained in chemistry but without formal education in medicine. As one of that very class, I venture to raise the question as to whether we have always sufficient catholicity. Is it not possible that we sometimes overlook the fact that we are training men to be physicians, not chemists? In our very righteous indignation at the inefficiency of the old "medical chemistry" may we not have swung the pendulum a little too far away from the point of practical contact?

To the last question it may be replied with perfect logic that when we have laid an adequate foundation of sound theory it is for the physiologist, the pathologist and the internist to build upon it according to the particular needs of his subject. But, like the gas laws, this logic applies strictly only under ideal conditions. As a practical fact the pathologists, internists, etc., concerned are not infrequently men who have succeeded less on account of any knowledge of chemical principles than in spite of the handicap of their inadequate instruction in that subject. Most of us have known chemists, the great men of a passing 
generation, who having passed middle age before the advent of certain theories were entirely unable to use them in their reasoning although according formal acceptance. It were hardly fair to prescribe a more rigid requirement for our medical teachers of the present, though we may expect much more' of those now in the making. In the meanwhile, shall the student be allowed to miss much which is essential because the chemistry teacher prefers to draw about himself the white mantle of pure science and pass by on the other side?

Another question occurs. By inference there has already been suggested a need for teachers trained both in chemistry and in medicine. The large number of published researches by "John Doe, Ph.D., and James Smith, M.D." suggests another field of usefulness for the man who can unite the training indicated by these two degrees, while the increased application of chemical analyses to clinical diagnosis is a third factor in creating a demand for such preparation. The last factor is worthy of some special consideration. This increased demand for chemical data in diagnosis is already marked, but it has only commenced. There must be men to do the work-and the practician is excluded. The methods concerned are quantitative and their usefulness depends upon the accuracy of the results. Even assuming the possibility of developing a quantitative conscience in a medical student within the available time, analytical efficiency can not be maintained by sporadic effortsand the maintenance of regular quantitative work is incompatible with the practise of medicine. The requisite skill can be provided only by chemically trained men who give it their regular attention, and this is the way it is actually working out. The movement toward concentrating medical practise in hospitals is already well under way; an eminent authority has predicted that it will soon become universal. Already the hospitals are providing their corps of clinical chemists. Is it not time to make some special educational provision for the particular kind of combined training which will peculiarly fit men to dis- charge the functions of teaching, research and clinical control which have been indicated?

It may be suggested that adequate preparation for such work may be secured even now by pursuing the courses leading to the Ph.D. degree in chemistry and subsequently going on to the M.D. A few men do this and we recognize the a priori advantages which they possess over those who have only the one degree. But it is not economically sound to advocate this regimen for all who would so qualify themselves. Of the four years required for the medical degree (already it is five in those institutions which set the standards for to-morrow) more than half the time is devoted to the subjects of anatomy, surgery, obstetrics and minor allied subjects to which present or prospective chemical methods are only remotely related. It would appear both desirable and feasible to provide in our medical schools (or some of them) a special course for men already thoroughly trained in chemistry. Within two years could be compassed intensive courses in biology, physiology, advanced physiological chemistry, pathology, bacteriology and internal medicine with very brief attention to such portions of other branches as might appear desirable. With a bachelor's degree including as much chemistry as is now obtainable would it not be possible to arrange such a special course as suggested and, following this with a year of research, grant at the end of seven years the Ph.D., D.Sc., or a new degree of equal dignity?

A few years ago the Division of Organic Chemistry held a symposium upon methods of teaching that subject. If there are enough of the members of this Biochemical Division who are interested in the suggestions raised, or in allied considerations, it might be of advantage to provide at some future meeting for a similar free discussion of the whole matter. Out of such a frank canvassing of the situation there should come results which would enable the chemistry of the future to offer even more substantial contributions than the chemistry of the past has made to the science and art of medicine.

L. Junius Desha

Memphis, TenN. 